\title{
ANALITIKA
}

Available online http://ojs.uma.ac.id/index.php/ analitika

\section{Hubungan antara Self Regulated Learning dengan Kematangan Karir pada Siswa SMA}

\section{The Relationship Between Self Regulated Learning with Career Maturity in Students SMA}

\author{
Azhar Aziz \& Khaulah Aisyah Putri Siswanto*
}

Magister Psikologi, Program Pascasarjana, Universitas Medan Area, Indonesia*Corresponding

author: E-mail: khaulahaisyah18@gmail.com

\begin{abstract}
Abstrak
Penelitian ini bertujuan untuk melihat hubungan self regulated learning dengan kematangan karir pada siswa kelas XI MAN 2 MODEL MEDAN. Subjek dalam penelitian ini adalah siswa kelas XI jurusan IPA, yang mendapat ranking 1-10 yang berjumlah 100 siswa. Teknik pengambilan sampel menggunakan teknik purposive sampling. Pengambilan data dilakukan dengan menggunakan dua skala, yaitu skala self regulated learning dan skala kematangan karir. Analisis data menggunakan teknik korelasi (rxy) sebesar 0.543 dengan p = 0,000< 0,005, artinya terdapat hubungan positif dan signifikan antara self regulated learning dengan kematangan karir siswa kelas XI, yang menunjukkan bahwa semakin tinggi self regulated learning siswa maka semakin tinggi kematangan karirnya. Sebaliknya semakin rendah self regulated learning siswa maka semakin rendah kematangan karirnya. Adapun koefisien determinasi dari korelasi tersebut sebesar R2 $=0,294$ artinya self regulated learning memberikan sumbangan terhadap kematangan karir sebesar 29\%. Hasil penelitian ini sesuai hipotesis dengan hasil penelitian di lapangan.
\end{abstract}

Kata Kunci : Self Regulated Learning, Kematangan Kari, Siswa.

\begin{abstract}
This research aims to look at the relationship between the self regulated learning with career maturity among 11th grade students in MAN 2 MODEL MEDAN. One hundred students majoring in science and has has the top ten ranking in its class, participated in this study. A purposive sampling technique was used in this study and the data were revealed through self regulated learning scale and career maturity scale. A product moment correlation was used to analyzed the data and the result showed a significant positive correlation ( $r x y=0.543, p=0.00)$ which means that the more self regulated, the higher level of maturity of their career. In contrast the lower self regulated learning then the lower the maturity of his career. As for the determination of the correlation coefficient of R2=0,294 meaning self regulated learning contribute to career maturity amounting to 29\%. The result of this research hypothesis according with the research result in the field.

Keywords: SelfRegulated Learning; Career Maturity; Student
\end{abstract}

How to Cite: Azhar, A. \& Siswanto, K,A.P. (2018). Hubungan antara Self Regulated Learning dengan Kematangan Karir pada Siswa SMA. Analitika, 10 (1): 7 - 13 


\section{PENDAHULUAN}

Pendidikan merupakan bagian yang sangat penting untuk meningkatkan kualitas sumber daya manusia Indonesia yang semakin hari semakin dihadapkan pada persaingan, bukan saja dari bangsa lain yang sudah lebih maju, namun juga di antara sesama rakyat Indonesia yang semakin banyak jumlahnya. Di era globalisasi ini, tujuan-tujuan dan programprogram pendidikan dituntut untuk secara dinamis dapat menyesuaikan diri dengan perubahan yang sangat cepat untuk diikuti. Bekal masa depan seseorang dapat diperoleh melalui pendidikan formal. Sebagaimana tercantum dalam UndangUndang Sistem Pendidikan Nasional nomor 20 tahun 2003 pada BAB II pasal 3 yang membahas tentang tujuan pendidikan nasional. Hal tersebut menuntut negara untuk berperan memberikan pendidikan yang layak kepada warga negaranya agar cita-cita pendidikan nasional dapat terwujud, dimana negara harus dapat memberikan pengajar dan kurikulum yang sesuai dengan perkembangan individu. Pendidikan jenjang Sekolah Menengah Atas (SMA) menurut Badan Pusat Statistik menempatkan siswa dengan rentang usia antar 16 sampai 18 tahun, yang digunakan sebagai cara menghitung angka partisipasi sekolah di Indonesia.

Masa remaja merupakan periode yang penting, periode peralihan, periode perubahan, usia bermasalah, mencari identitas, usia yang menimbulkan ketakutan, masa yang tidak realistik dan ambang masa dewasa (Hurlock, 1998).

Remaja yang duduk di bangku SMA memiliki tugas perkembangan yang seharusnya dapat dicapai, individu diharapkan mampu mempersiapkan diri untuk menapaki masa mendatang. Hal ini ditunjukkan dengan kemampuan siswa mengenali potensi diri dan arah minatnya untuk suatu bidang karir yang ingin dijalani kelak serta memilih jurusan yang sejalan dengan bidang karirnya. Pada kenyataannya tidak banyak siswa yang mengerti akan potensi serta kemampuan yang dimilikinya sehingga dalam penentuan karir akan cukup mengalami kesulitan. Ketidaktahuan akan tujuan sekolah pada masa SMA terlihat dari data Biro Pusat Statistik (Sumber: BPS-RI, Susenas 2003-2011) menunjukan bahwa angaka partisipasi sekolah untuk siswa SMA atau rentang usia 16-18 tahun pada tahun 2011 diseluruh Indonesia hanya 57,58\%. Angaka ini lebih sedikit dibandingkan pada tahapan SD (6-12 tahun) sekitar 97,58\% dan SMP (13-15 tahun) yang menunjukan prosentase 87,78\%. Rendahnya kesadaran tentang tujuan pendidikan nasional membuat individu kesulitan dalam mencapai masa dapan. Hal tersebut dirasakan karena pendidikan akan berpengaruh pada pola pikir serta pekerjaan seseorang.

Kematangan karir merupakan proses yang berlangsung terus menerus. Kematangan karir lebih memerlukan persiapan perencanaan yang matang daripada sekedar mendapatkan sesuatu yang sifatnya sementara. Setiap manusia selalu dihadapkan dengan keputusankeputusan akan karir dan tidak dapat melepaskan diri dari masalah tersebut dalam waktu yang singkat, dan jarang yang dapat memecahkannya secara tuntas (Super, 1980). Keputusan akan karir banyak dilakukan tanpa mempertimbangkan kemampuan, minat 
dan kepribadian individu. Ada kecenderungan individu mengikuti pilihan orangtua atau teman, dengan dasar popularitas pekerjaan atau identifikasi dengan orangtua sehingga siswa dalam usahanya untuk mencapai kematangan karir yang diinginkan sering mengalami hambatan.

Kematangan karir dapat diartikan sebagai keberhasilan individu untuk menyelesaikan tugas-tugas perkembangan karir yang khas bagi tahap perkembangan tertentu. Dia juga menjelaskan bahwa individu dikatakan matang atau siap untuk membuat keputusan akan karir jika pengetahuan yang dimilikinya untuk membuat keputusan akan karir didukung oleh informasi yang kuat mengenai pekerjaan berdasarkan eksplorasi yang telah dilakukan (Winkel dan Hastuti, 2007).

Hurlock (1998) bahwa siswa SMA mulai memikirkan masa depan mereka secara sungguh-sungguh. Agar para siswa dapat memilih karir yang tepat, dalam hal ini adalah keputusan tentang pendidikan lanjutan, siswa memerlukan tingkat kematangan karir yang baik.

Super (dalam Dillard, 1985) masa remaja termasuk ke dalam tahap eksplorasi pada tingkat tentatif. Pada tahap ini faktor-faktor yang diperhitungkan dalam pemilihan karir adalah kebutuhan, minat, kapasitas, nilainilai dan kesempatan (peluang). Tahap ini merupakan tahap paling penting bagi transisi remaja.

Siswa pada jenjang sekolah menengah atas (SMA) dihadapkan pada pilihan apakah ia akan melanjutkan pendidikannya ke jenjang perguruan tinggi, langsung terjun ke dunia pekerjaan, dan lain sebagainya. Siswa SMA tergolong pada fase perkembangan remaja, dimana remaja dihadapkan pada berbagai pertanyaan yang menyangkut tentang keberadaan dirinya, masa depannya, peran sosialnya dalam keluarga maupun masyarakat, serta kehidupannya dalam beragama. Untuk memilih dan merencanakan karir yang tepat, dibutuhkan kematangan karir, yaitu meliputi perencanaan, eksplor, pengumpulan informasi, dan pengambilan keputusan.

Namun, di sisi lain siswa SMA dalam hal ini remaja tidak dengan mudah menyelesaikan tugas perkembangan karirnya. Siswa seringkali mempunyai permasalahan yang berhubungan dengan kelanjutan studi atau pekerjaan setelah lulus. Hal ini sesuai dengan pendapat Supriatna (2009) masalah-masalah yang sering muncul diantaranya kebingungan dalam memilih program studi, memilih jurusan di perguruan tinggi, menentukan cita-cita atau bahkan tidak memahami bakat dan minat yang dimiliki, dan merasa cemas untuk mendapat pekerjaan setelah tamat sekolah. Kebingungan yang sering dialami siswa diantaranya pada saat mereka akan memilih jurusan di kelas XI ataupun memutuskan pilihan pendidikan setelah lulus SMA, ditambah adanya perasaan cemas dalam menghadapi masa depan dan dunia kerja.

Hal itu diperkuat dari penelitian Prihantoro (2007) yang menyebutkan siswa kelas $\mathrm{X}$ SMAN 2 Majalengka sebagian besar memiliki kemampuan merencanakan karir yang rendah yaitu $27,8 \%$. Penelitian tersebut juga diperoleh data bahwa dari sembilan kemampuan yang harus dimiliki oleh remaja dalam 
merencanakan karir, kemampuan dalam hal kemandirian pengambilan keputusan karir adalah yang terendah.

Penelitian El Hami dkk (2006) menunjukkan hasil yang relatif sama yang menunjukkan bahwa tingkat kematangan karir pada calon mahasiswa yang menjadi responden pada kedua fakultas masih berada pada taraf belum matang. Hal ini menunjukan bahwa kematangan karir siswa SMA masih rendah, dimana pengetahuan dan keinginan untuk memperoleh informasi dan wawasan tentang studi lanjutan serta kemampuan dalam pengambilan keputusan yang berkaitan.

Siswa yang menentukan tujuan dalam pendidikan dan berinisiatif mengarahkan pikiran dan perilakunya untuk berusaha mencari pilihan jurusan atau pilihan karir kemudian berhasil menentukan pilihan jurusan perguruan tinggi yang ingin digelutinya sebagai langkah awal menuju karir yang diinginkannya. Namun, ada pula siswa yang menggunakan strategi belajar tetapi masih bingung untuk menentukan pilihan jurusan perguruan tinggi dan karir yang ingin ia capai di masa depan. Dalam ilmu psikologi, usaha yang dilakukan siswa untuk mengarahkan serta mengatur perilaku dan tindakannya dalam konteks belajar disebut dengan self-regulated learning.

Self regulated learning merupakan usaha mengarahkan pikiran,perasaan, serta perilaku untuk mencapai tujuan akademik yang diinginkan (Zimmerman, 2000; Pintrich, 2004). Menurut Pintrich (2000), perspektif self-regulated learning merupakan perspektif yang lebih mencakup keseluruhan dalam proses belajar yang tidak hanya melibatkan kognitif, tetapi juga faktor motivasi dan afeksi, serta konteks sosial.

\section{METODE PENELITIAN}

Populasi yang digunakan dalam penelitian ini adalah siswa kelas XI MAN 2 MODEL MEDAN jurusan IPA yang berjumlah 300 siswa yang terdiri dari 10 kelas. Sampel yang digunakan untuk penelitian ini adalah 100 siswa. Teknik pengambilan sampel yang digunakan adalah teknik purposive sampling, yang memiliki karakteristik, yaitu siswa/i kelas XI MAN 2 MODEL MEDAN, siswa/i yang mendapat ranking 1-10 di kelasnya masing-masing, dan siswa yang berada di jurusan IPA.

Pengumpulan data yang digunakan adalah metode skala dengan skala model Likert. Skala terdiri dari aitem-aitem yang disusun berdasarkan aspek-aspek konstruk yang akan dikur. Aitem-aitem dalam skala terdiri dari pernyataanpernyataan yang bersifat favorable dan unfavorable. Skala yang digunakan dalam penelitian berupa dua skala likert, yaitu skala kematangan karir dan self regulated learning.

Skala kematangan karir dalam penelitian ini disusun berdasarkan aspekaspek yang dikemukakan oleh Super (1980), yaitu career planning (perencanaan karir), career exploration (eksplorasi karir), decision making (pengambilan keputusan) dan Informational Gathering (pengumpulan informasi tentang karir).

Skala self regulated learning dalam penelitian ini disusun berdasarkan aspekaspek yang dikemukakan oleh 
Zimmerman (1989), yaitu metakognisi, motivasi, dan perilaku

Definisi operasional kematangan karir adalah kesiapan dan kemampuan siswa dalam membuat keputusan karir sesuai dengan tahap perkembangan karirnya. Tinggi rendahnya kematangan karir merupakan skor yang diperoleh dari pengukuran kematangan karir melalui skala kematangan karir yang dikembangkan dari empat dimensi kematangan karir yaitu Planfulness (perencanaan karir), Decision Making (pengambilan keputusan), Exploration (eksplorasi karir), dan Information Gathering (pengumpulan informasi tentang karir).

Dan definisi operasional self regulated learning adalah sebuah konsep mengenai bagaimana seseorang peserta didik menjadi regulator atau pengatur bagi belajarnya sendiri. Selain itu, self regulated learning diartikan juga sebagai pengawasan atas perilaku dalam proses belajar sebagai hasil dari proses internal dari tujuan, perencanaan, dan penghargaan diri sendiri atas prestasi yang telah diraih. Self regulated learning diungkap dengan skala yang terdiri dari tiga aspek, yaitu: (1) aspek metakognisi merupakan kemampuan untuk dapat memahami hal yang dibutuhkan dalam menghadapi situasi belajar, (2) aspek motivasi merupakan pendorong yang ada pada individu untuk dapat mengarahkan individu dalam mengorganisisr aktivitas belajarnya, dan (3) aspek perilaku yang merupakan upaya individu untuk memilih, menyeleksi dan memanfaatkan strategi belajar dan lingkungan yang mendukung aktivitas belajarnya.
Data yang telah terkumpul akan dianalisis secara statistik dengan menggunakan teknik korelasi Product Moment. Dilakukan uji asumsi seperti uji normalitas dan uji linieritas.

\section{HASIL DAN PEMBAHASAN}

Hasil uji normalitas sebaran terhadap terhadap variabel kematangan karir menghasilkan nilai $\mathrm{p}=0,155$ ( $p>0,050$ ) Hasil uji berdasarkan kaidah menunjukkan sebaran kematangan karir adalah normal. Hasil uji normalitas sebaran terhadap variabel self regulated learning menghasilkan nilai $\mathrm{p}=0,075$ ( $\mathrm{p}>$ 0,050 ) hasil uji berdasarkan kaidah menunjukkan sebaran self regulated learning adalah normal. Hasil uji asumsi linieritas antara self regulated learning dengan kematangan karir mempunyai nilai deviant from linearity $\mathrm{F}$ Beda = 84,340 dan $\mathrm{p}$ Beda $=0,000<0.050$ yang berarti hubungannya dinyatakan linier. Berdasarkan hasil analisis dengan metode analisis korelasi product moment, diketahui bahwa terdapat hubungan positif yang signifikan antara self regulated learning dengan kematangan karir, dimana $r x y=0,543 ; p<0,050$. Artinya, semakin tinggi self regulated learning, maka semakin tinggi kematangan karir. Berdasarkan hasil penelitian ini, maka hipotesis yang di ajukan dinyatakan diterima.

Diterimanya hipotesis ini erat kaitannya dengan pendapat Zimmerman menjelaskan bahwa siswa yang memiliki self regulated learning yang baik, dapat membuat keputusan sendiri tanpa di pengaruhi oleh orang lain, dapat mengandalkan diri, dan lebih bertanggung jawab pada keputusan yang telah dibuat. 
Hasil penelitian ini relevan dengan hasil penelitian yang dilakukan oleh Lativa Hartiningtyas, Purnomo, Hakkun Elmunsyah (2016) mengenai hubungan antara self regulated learning dan locus of control internal dengan kematangan vocational siswa SMK mengungkapkan bahwa terdapat hubungan antara self regulated learning dengan kematangan karir. Peserta didik yang memiliki sikap mandiri dalam belajar dapat mengetahui apa yang harus dilakukan agar belajarnya efektif dan dapat mencapai tujuan yang diharapkan. Individu mengetahui apa saja yang harus diputuskan dalam belajar untuk mencapai kompetensi tertentu. Dengan demikian individu yang memiliki self regulated learning biasanya memiliki kematangan karir yang berhubungan dengan apa yang akan dilakukan di masa mendatang.

Dari hasil penelitian self regulated learning memberi pengaruh 29\% terhadap kematangan karir. Dari hasil penelitian ini dinyatakan bahwa masih terdapat $71 \%$ pengaruh dari faktor lain terhadap kematangan karir dimana faktor itu adalah bio-sosial, lingkungan, kepribadian, dan vocational.

Berdasarkan hasil penelitian ini sama dengan fenomena yang ditemukan peneliti di lapangan, bahwa siswa yang memiliki self regulated learning yang baik maka ia akan matang dalam karirnya baik itu dalam memilih jurusan di perguruan tinggi selanjutnya ataupun memilih dipekerjaan di bidang yang ia minati

\section{SIMPULAN}

Berdasarkan hasil penelitian ini, bahwa terdapat hubungan yang positif dan signifikan antara self regulated learning dengan kematangan karir pada siswa Man 2 Model Medan. Dimana rxy $=0,543 ; p=$ 0,000 . Artinya, semakin tinggi self regulated learning pada siswa, maka semakin tinggi kematangan karir.

Koefisien dterminan $\left(r^{2}\right)=29$,4. Ini menunjukkan bahwa self regulated learning memiliki kontribusi 29\% terhadap kematangan karir siswa kelas XI Man 2 Model.

Secara umum, self regulated learning pada siswa Man 2 Model Medan tergolong tinggi. Hal itu terlihat dari hasil rata-rata mean hipotetik < rata-rata mean empirik ( 87,5 < 106,64) dengan selisih melebihi satu SD/SB. Kematangan karir pada siswa SMA Negeri 1 Medan juga tergolong tinggi. Hal itu terlihat dari hasil rata-rata mean hipotetik < rata-rata mean empirik $(100<127,12)$ dengan selisihnya melebihi 1 SD/SB.

\section{DAFTAR PUSTAKA}

Dillard, J. M. (1985). Life Long Career Planning. Ohio: Charles E. Meril Publishing Co.

Hartiningtyas, Purnomo, Elmunsyah. (2016). Hubungan Antara Self Regulated Learning dan Locus Of Control Internal Dengan Kamatangan Vocational Siswa SMK. Jurnal Pendidikan. Vol. 1, No. 6

Hurlock, E. B. (1998). Psikologi Perkembangan: Suatu Pendekatan Sepanjang Rentang Kehidupan (Edisi Kelima). Jakarta: Erlangga

Pintrich, P. R. (2000). The role of goal organitation in self regulated learning. In M. Boekarts, P. R. Pintrich, \& M. Zaidner (Eds). Hnadbook of self regulation (pp. 451503). San Diego: Academic Press.

Prihantoro, S. (2007). Program Bimbingan untuk Mengembangkan Kemampuan Perencanaan Karir Remaja (Studi Terhadap Siswa Kelas X SMAN 2

Super, D. E. (1980). A Life-Span, Life-Space Approach to Career Development. Journal of Vocational Behavior 16. 282-298 Academic Press. Inc. 
Supriatna, Mamat. (2009), Layanan Bimbingan Karir di Sekolah Menengah. Bandung: Depdiknas dan UPI.

Super, D. E. (1980). A Life-Span, Life-Space Approach to Career Development. Journal of Vocational Behavior 16. 282-298 Academic Press.Inc.

Supriatna, Mamat. (2009), Layanan Bimbingan Karir di Sekolah Menengah. Bandung: Depdiknas dan UPI.
Winkel \& Hastuti. (2013). Bimbingan dan konseling di institusi pendidikan edisi revisi. Yogyakarta : Media Abadi

Zimmerman, B. J. (1989). A Social Cognitive View of Self-Regulated Academic Learning. Journal of Education Psychology. 81, 329339 . 